\title{
Incorporação de gesso para correção da salinidade e sodicidade de solos salino-sódicos
}

\author{
Antonio N. Tavares Filho ${ }^{1}$, Maria de F. C. Barros ${ }^{1}$, \\ Mario M. Rolim ${ }^{1} \&$ Ênio F. de F. e Silva ${ }^{1}$
}

\begin{abstract}
RESU M 0
Com o objetivo de avaliar o efeito da aplicação do gesso nas características químicas de solos salinosódicos coletados no Perímetro Irrigado do Moxotó, localizado no município de Ibimirim, PE, um experimento foi realizado em colunas de solo instaladas no Laboratório de Mecânica do Solo e Aproveitamento de Resíduo da Universidade Federal Rural de Pernambuco. Os tratamentos foram dispostos em um delineamento inteiramente casualizado com esquema fatorial de dois solos $\left(\mathrm{S}_{1}\right.$ e $\mathrm{S}_{2}$ ) e sete níveis da necessidade de gesso $(50,75,100,125,150,175$ e $200 \%)$ determinado pelo M étodo de Laboratório Schoonover-M 1. O gesso foi incorporado aos solos, em três repetições, totalizando 42 unidades experimentais. As variáveis avaliadas foram: i) condutividade elétrica (CE), ii) cátions solúveis e iii) relação de adsorção de sódio (RAS) no extrato de saturação do solo. 0 nível de $100 \%$ da necessidade de gesso causou diminuição da sodicidade para valores de RAS $<13\left(\mathrm{mmol} \mathrm{L}^{-1}\right)^{1 / 2}$ apresentando-se como método eficiente na redução dos teores de sódio em áreas afetadas por sais A lâmina de lixiviação equivalente a três vezes o volume de poros (3VP) reduziu a condutividade elétrica (CE) no extrato de saturação para valores $<4 \mathrm{dS} \mathrm{m}^{-1}$, razão por que foi indicada para a correção da salinidade dos solos em estudo.
\end{abstract}

Palavras-chave: relação de adsorção de sódio, lâmina de lixiviação, necessidade de gesso

\section{Incorporation of gypsum to correct the salinity and sodicity of saline-sodic soils}

\begin{abstract}
Aiming to evaluate the effect of gypsum on the modification of chemical properties of saline-sodic soils collected in the Irrigated Perimeter of Ibimirim-PE, an experiment was carried out in soil columns installed at the Soil Mechanics and Residue Recovery Laboratoy at the U niversidade Federal Rural de Pernambuco. The treatments were arranged in a completely randomized design with factorial arrangement of two soils $\left(S_{1}\right.$ and $\left.S_{2}\right)$ and seven levels of gypsum requirement $(50,75,100,125,150,175$ and $200 \%)$ determined by the Laboratory Method Schoonover-M 1. The gypsum was incorporated in to the soils, in three replications, totaling 42 experimental units. The parameters evaluated were: electrical conductivity (EC), soluble cations and sodium adsorption ratio (SAR) in the saturation extract of soil. The level of the $100 \%$ of gypsum requirement caused decreased in sodicity values of SAR under $13\left(\mathrm{mmol} \mathrm{L}^{-1}\right)^{1 / 2}$, presenting itself as an effective method in reducing the levels of sodium in areas affected by salt. The water depth equivalent to three times of the volume of pores (3VP) decreased the EC of saturation extract to values $<4 \mathrm{dS} \mathrm{m}^{-1}$, being so indicated for soil salinity correction.
\end{abstract}

Key words: sodium adsorption ratio, water depht, gypsum requirement 


\section{INTRODUÇÃO}

Normalmente, os solos afetados por sais ocorrem nas regiões áridas e semiáridas. Esses solos contêm sais solúveis e/ou sódio trocável passíveis de reduzir significativamente o desenvolvimento e, em consequência, a produtividade das culturas (Silveira et al., 2008; Barros et al., 2009).

Em condições naturais a acumulação de sais no solo é resultado das altas taxas de evaporação, baixa precipitação pluviométrica, de características do material de origem e das condições geomorfológica e hidrogeológica locais (Richards, 1954; Barros et al., 2004).

Solos afetados por sais ocorrem extensivamente sob condições naturais porém os problemas mais sérios de salinização são representados por solos anteriormente produtivos mas que se tornam salinos devido à irrigação e drenagem ineficientes. Esta salinização é comumente chamada salinização secundária ou antrópica (Barros et al., 2005).

Extensas áreas irrigadas em todo o mundo vêm apresentando diminuição de suas produções em decorrência do excesso de sais (Keiffer \& Ungar, 2002; Horney et al., 2005; Leal et al., 2008).

O uso inadequado das técnicas da irrigação e drenagem em áreas sensíveis ao processo de salinização natural pode proporcionar, ao longo do tempo, a expansão de áreas com problemas de sais e sódio trocável, como se tem registrado no Agreste e Sertão Pernambucano culminando, quase sempre, no abandono de lotes em Perímetros Irrigados, gerando sérios problemas de ordem social e econômica.

Barros et al. (2006) citam que a quantidade de gesso necessária para reduzir a sodicidade dos solos salino-sódicos e sódicos pode ser calculada em função da percentagem de sódio trocável que se deseja substituir, da capacidade de troca de cátions do solo e da profundidade do solo a ser recuperada ou pode ser determinada por teste de laboratório envolvendo o equilíbrio entre o solo e uma solução saturada de gesso.

O uso de corretivos químicos, especialmente o gesso, de baixo custo, parece ser a forma mais prática de correção de solos salino-sódicos (Oliveira et al., 2002; Ruiz et al., 2004).

No nordeste brasileiro aproximadamente $30 \%$ da área total dos Perímetros Irrigados do estado de Pernambuco implantados pelo Departamento Nacional de Obras de Contra as Secas DNOCS estão afetados por altos teores de sódio solúvel e trocável. Este mesmo problema é verificado no Ceará e na Paraíba, que apresentam 25 e 40\% das áreas irrigadas salinizadas e/ou sodificadas (Fageira \& Gheyi, 1997). Considerando o investimento efetuado nas áreas irrigadas, em média de quinze mil dólares por hectare, verifica-se a viabilidade econômica da recuperação desses solos.

Ante o exposto, pode-se concluir que os resultados encontrados no estudo poderão ajudar na transmissão de técnicas e conhecimentos para a resolução do problema de lidar com o manejo de solos afetados por sais do Nordeste do Brasil, tendo em vista o aumento das áreas disponíveis para agricultura irrigada torna-se evidenciado, portanto, que a correção desses solos se faz necessária para sua reincorporação ao sistema de produção, garantindo a permanência do agricultor na zona semiárida evitando, ao mesmo tempo, aumento do êxodo-rural.

O objetivo desta pesquisa foi avaliar a eficiência do gesso mineral na correção de solos salino-sódicos em função do deslocamento do sódio trocável determinado pelo método de laboratório Shoonover M-1, além de testar o efeito da lâmina de lixiviação na diminuição do caráter salino dos solos em estudo.

\section{Material E MÉTODOS}

As amostras de solos $\left(\mathrm{S}_{1}\right.$ e $\left.\mathrm{S}_{2}\right)$ afetadas por sais e sódio coletadas no Perímetro Irrigado do Moxotó, no município de Ibimirim, PE, foram conduzidas ao Laboratório de Mecânica do Solo e Aproveitamento de Resíduo da Universidade Federal Rural de Pernambuco (UFRPE), onde foram retirados os torrões para determinação da densidade do solo; posteriormente, as amostras foram secas ao ar, destorroadas e passadas em peneira de malha de $2 \mathrm{~mm}$ para caracterização física e química. A amostragem foi realizada segundo o procedimento descrito por Magalhães (1987). Amostras representativas de cada lote (amostras compostas) foram coletadas na profundidade de $400-\mathrm{cm}$.

A pasta saturada foi preparada obedecendo à metodologia descrita por Richards (1954). No extrato de saturação do solo foram determinados: i) condutividade elétrica (CE), ii) cálcio e o magnésio solúveis por espectrofotometria de absorção atômica, iii) sódio e o potássio por fotometria de chama, iv) carbonato e bicarbonato por titulação com $\mathrm{H}_{2} \mathrm{SO}_{4} 0,005 \mathrm{~mol} \mathrm{~L}^{-1} \mathrm{e}$ v) cloreto por titulação com $\mathrm{AgNO}_{3} 0,025 \mathrm{~mol} \mathrm{~L}^{-1}$ (EMBRAPA, 1997). O ânion sulfato foi determinado por colorimetria com precipitação com cromato de bário, seguindo a metodologia de Magalhães (1987).

Obteve-se a relação de adsorção de sódio (RAS) usandose a expressão: $\mathrm{RAS}=\left(\mathrm{Na}^{+}\right) /\left[\left(\mathrm{Ca}^{++}+\mathrm{Mg}^{++}\right) / 2\right]^{1 / 2}$ : para a determinação dos níveis da necessidade de gesso (NNG), foi usada uma modificação do Método de Laboratório de Schoonover M-1 (Shoonover, 1952), desenvolvida por Barros \& Magalhães (1989) para solos salino-sódicos de Pernambuco. Os resultados das análises do extrato de saturação dos solos se apresentam na Tabela 1 .

Tabela 1. Análise do extrato da pasta de saturação das amostras de solos

\begin{tabular}{lcrr}
\hline \multicolumn{1}{r}{$\begin{array}{c}\text { Atributo } \\
\text { químico }\end{array}$} & \multirow{2}{*}{ Unidade } & \multicolumn{2}{c}{ Solo } \\
\cline { 3 - 4 } $\mathrm{Ca}^{++}$ & & $\mathbf{S}_{\mathbf{1}}$ & \multicolumn{1}{c}{$\mathbf{S}_{\mathbf{2}}$} \\
$\mathrm{Mg}^{++}$ & $\left(\mathrm{mmol}_{\mathrm{c}} \mathrm{L}^{-1}\right)$ & 5,06 & 7,58 \\
$\mathrm{Na}^{+}$ & $\left(\mathrm{mmol}_{\mathrm{c}} \mathrm{L}^{-1}\right)$ & 7,08 & 53,15 \\
$\mathrm{~K}^{+}$ & $\left(\mathrm{mmol}_{\mathrm{c}} \mathrm{L}^{-1}\right)$ & 47,40 & 313,01 \\
$\mathrm{Cl}^{-}$ & $\left(\mathrm{mmol}_{\mathrm{c}} \mathrm{L}^{-1}\right)$ & 0,77 & 1,28 \\
$\mathrm{SO}_{4}{ }^{-}$ & $\left(\mathrm{mmol}_{\mathrm{c}} \mathrm{L}^{-1}\right)$ & 54,14 & 337,83 \\
$\mathrm{CO}_{3}{ }^{-}$ & $\left(\mathrm{mmol}_{\mathrm{c}} \mathrm{L}^{-1}\right)$ & 5,56 & 26,93 \\
$\mathrm{HCO}{ }_{3}$ & $\left(\mathrm{mmol}_{\mathrm{c}} \mathrm{L}^{-1}\right)$ & 0,00 & 0,00 \\
$\mathrm{CE}$ & $\left(\mathrm{mmol}_{\mathrm{c}} \mathrm{L}^{-1}\right)$ & 0,97 & 0,52 \\
$\mathrm{RAS}$ & $\left(\mathrm{dS} \mathrm{m}^{-1}\right)$ & 6,22 & 35,96 \\
$\mathrm{NG}$ & $\left(\mathrm{mmol} \mathrm{L}^{-1}\right)^{1 / 2}$ & 19,24 & 56,80 \\
\hline
\end{tabular}

CE - condutividade elétrica do extrato da pasta saturada; RAS - relação de adsorção de sódio; NG - necessidade de gesso 
Através da metodologia da EMBRAPA (1997), foram avaliadas as seguintes características físicas: granulometria, densidade das partículas, densidade do solo, condutividade hidráulica saturada com amostra deformada e grau de floculação das argilas. A composição granulométrica foi obtida após lavagem com álcool a $60 \%$, até reação negativa dos cloretos. Os resultados das análises físicas podem ser visualizados na Tabela 2.

Tabela 2. Características físicas das amostras de solos

\begin{tabular}{lccc}
\hline \multirow{2}{*}{ Atributo físico } & \multirow{2}{*}{ Unidade } & \multicolumn{2}{c}{ Solo } \\
\cline { 3 - 4 } & & $\mathbf{S}_{\mathbf{1}}$ & $\mathbf{S}_{\mathbf{2}}$ \\
Areia & $(\%)$ & 45,20 & 9,45 \\
Silte & $(\%)$ & 28,07 & 44,11 \\
Argila & $(\%)$ & 26,73 & 46,44 \\
Ko & $\left(\mathrm{cm} \mathrm{h}^{-1}\right)$ & 0,12 & 0,00 \\
Dp & $\left(\mathrm{g} \mathrm{cm}^{-3}\right)$ & 2,43 & 2,65 \\
Ds & $\left(\mathrm{g} \mathrm{cm}^{-3}\right)$ & 1,50 & 1,58 \\
GF & $(\%)$ & 27,20 & 19,14 \\
PT & $\left(\mathrm{m}^{3} \mathrm{~m}^{-3}\right)$ & 0,38 & 0,41 \\
Classe textural & & Franco-argiloso & Argila-siltosa \\
\hline
\end{tabular}

Ko - condutividade hidráulica saturada; Dp - densidade da partícula; Ds - densidade do solo; GF - grau de floculação; PT - porosidade total

Os tratamentos foram dispostos em um esquema fatorial de dois solos $\left(\mathrm{S}_{1}\right.$ e $\left.\mathrm{S}_{2}\right)$ e sete níveis da necessidade de gesso (50, $75,100,125,150,175$ e $200 \%)$. O gesso foi incorporado aos solos, em três repetições. As unidades experimentais foram constituídas de tubos em PVC com $10 \mathrm{~cm}$ de diâmetro e $30 \mathrm{~cm}$ de altura. Para conter as amostras de solos na base dos tubos, foram colocadas telas de náilon de $1 \mathrm{~mm}$ de malha.

As colunas de solo foram fechadas na parte inferior com tampas perfuradas no centro; neste furo foi instalada uma mangueira de $3 / 8$ polegadas para facilitar a coleta da solução drenada. Após a passagem em malha de $2 \mathrm{~mm}$ as amostras de solo $\left(\mathrm{S}_{1}\right.$ e $\left.\mathrm{S}_{2}\right)$ foram tratadas com os diferentes níveis de necessidade de gesso (NNG) e posteriormente acondicionadas nos tubos em PVC, na profundidade de $25 \mathrm{~cm}$, de modo a se aproximarem da densidade do solo; em seguida foi adicionada água deionizada lentamente, de cima para baixo, nas colunas, até atingir o ponto de saturação e posteriormente mantidas, pelo período de incubação de aproximadamente $24 \mathrm{~h}$, para estabelecimento do equilíbrio químico entre a fração sólida e a líquida.

A fim de se evitar as perdas por evaporação, os tubos em PVC foram vedados com filme plástico. Após o período de incubação as colunas de solo foram lixiviadas com água deionizada, mantendo-se uma lâmina constante de $2 \mathrm{~cm}$ tendose aplicado uma lâmina total de três vezes o volume de poros (3VP) e, às amostras de solo, o equivalente a $2.200 \mathrm{~mL}$, divididos em quatro frações de $550 \mathrm{~mL}$.

Após a lixiviação as colunas foram desmontadas e as amostras de solo secas ao ar, destorroadas e passadas em peneira de $2 \mathrm{~mm}$ de malha,determinando-se, em seguida, a condutividade elétrica (CE), os cátions solúveis e a relação de adsorção de sódio (RAS) no extrato de saturação dos solos.

Nas análises estatísticas utilizou-se o Sistema computacional SISVAR Versão 5.3 (Ferreira, 2008) cujos dados obtidos foram interpretados por meio de análise de variância e de regressão, testando-se diversos modelos estatísticos. O critério para escolha do modelo foi baseado no maior valor do coeficiente de determinação ajustado, precedido da significância dos coeficientes da equação de regressão.

\section{RESULTADOS E DISCUSSÃO}

Os valores obtidos no extrato de saturação dos solos para os cátions solúveis $\left(\mathrm{Ca}^{++}, \mathrm{Mg}^{++}, \mathrm{Na}^{+}, \mathrm{K}^{+}\right)$, condutividade elétrica (CE) e relação de adsorção de sódio (RAS) apresentaram grande variação após a aplicação dos tratamentos, em relação às suas características químicas originais (Tabela 3 ).

Tabela 3. Composição do extrato de saturação após aplicação de níveis da necessidade de gesso (N N G ) e da lâmina de lixiviação de três vezes o volume de poros (3VP) para as amostras de solos $\mathrm{S}_{1}$ e $_{2}$

\begin{tabular}{|c|c|c|c|c|c|c|c|}
\hline \multirow{2}{*}{ Solo } & \multicolumn{7}{|c|}{ NNG (\%) } \\
\hline & 50 & 75 & 100 & 125 & 150 & 175 & 200 \\
\hline & \multicolumn{7}{|c|}{$\mathrm{Ca}^{++}\left(\mathrm{mmol}_{\mathrm{c}} \mathrm{L}^{-1}\right)$} \\
\hline $\mathrm{S} 1$ & 1,36 & 3,14 & 6,42 & 9,19 & 10,44 & 11,14 & 12,32 \\
\hline \multirow[t]{2}{*}{$\mathrm{S} 2$} & 2,86 & 5,32 & 9,25 & 11,64 & 15,19 & 16,67 & 18,61 \\
\hline & \multicolumn{7}{|c|}{$\mathrm{Mg}^{++}\left(\mathrm{mmol}_{\mathrm{c}} \mathrm{L}^{-1}\right)$} \\
\hline S1 & 0,46 & 0,44 & 0,45 & 0,44 & 0,44 & 0,51 & 0,47 \\
\hline \multirow[t]{2}{*}{$\mathrm{S} 2$} & 0,79 & 0,85 & 0,78 & 0,78 & 0,82 & 0,81 & 0,82 \\
\hline & \multicolumn{7}{|c|}{$\mathrm{Na}^{+}\left(\mathrm{mmol}_{\mathrm{c}} \mathrm{L}^{-1}\right)$} \\
\hline S1 & 13,05 & 11,60 & 7,39 & 5,36 & 4,06 & 3,18 & 2,17 \\
\hline \multirow[t]{2}{*}{$\mathrm{S} 2$} & 31,31 & 27,10 & 21,6 & 18,26 & 15,51 & 13,48 & 12,61 \\
\hline & \multicolumn{7}{|c|}{$\mathrm{K}^{+}\left(\mathrm{mmol}_{\mathrm{c}} \mathrm{L}^{-1}\right)$} \\
\hline S1 & 0,03 & 0,03 & 0,03 & 0,04 & 0,04 & 0,03 & 0,04 \\
\hline \multirow[t]{2}{*}{$\mathrm{S} 2$} & 0,06 & 0,07 & 0,05 & 0,06 & 0,07 & 0,06 & 0,06 \\
\hline & \multicolumn{7}{|c|}{$\mathrm{CE}\left(\mathrm{dS} \mathrm{m}^{-1}\right)$} \\
\hline S1 & 1,45 & 1,62 & 1,68 & 1,70 & 1,81 & 1,90 & 2,10 \\
\hline \multirow[t]{2}{*}{$\mathrm{S} 2$} & 3,09 & 3,35 & 3,48 & 3,57 & 3,59 & 3,70 & 3,93 \\
\hline & \multicolumn{7}{|c|}{$\operatorname{RAS}\left(\mathrm{mmol}_{\mathrm{c}} \mathrm{L}^{-1}\right)^{3 / 2}$} \\
\hline S1 & 13,73 & 8,69 & 3,99 & 2,45 & 1,74 & 1,32 & 0,86 \\
\hline $\mathrm{S} 2$ & 23,20 & 15,44 & 9,65 & 7,33 & 5,48 & 4,55 & 4,03 \\
\hline
\end{tabular}

NNG - níveis da necessidade de gesso; CE - condutividade elétrica; RAS - relação de adsorção de sódio

Os resultados observados para cálcio demonstram que a concentração do elemento aumentou com a aplicação de níveis da necessidade de gesso (NNG) e da lâmina de lixiviação equivalente a três vezes o volume de poros (3VP). O incremento do íon cálcio no extrato de saturação pode ser explicado pelo aumento da fração de $\mathrm{Ca}^{++}$solúvel devido à dissolução do corretivo aplicado após aplicação dos tratamentos.

A relação entre os NNG e o $\mathrm{Ca}^{++}$solúvel foi testada e os dados apresentados comprovam que a concentração do cálcio se ajustou ao modelo de regressão linear para a quantidade de corretivo incorporado às amostras de solo (Figura 1). Referidos resultados estão similares ao reportado por Barros et al. (2004) que relatam incrementos na concentração de cálcio solúvel em pesquisa realizada com quatro amostras de solo salino-sódicos do Perímetro Irrigado de Custódia, em Pernambuco, Brasil.

As quantidades de potássio e magnésio no extrato de saturação foram muito baixas. Para o potássio, houve elevada lixiviação do cátion pela água de drenagem em virtude da sua fraca ligação química com os colóides do solo enquanto para o 


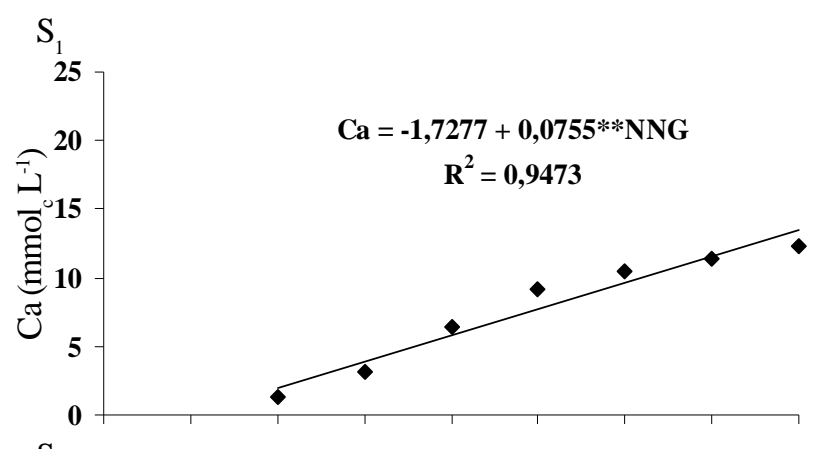

$$
\mathrm{S}_{2}
$$

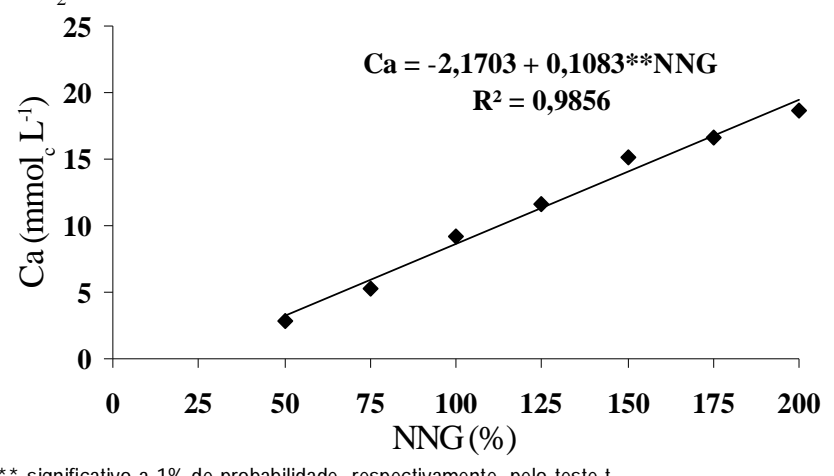

** significativo a $1 \%$ de probabilidade, respectivamente, pelo teste $t$

Figura 1. Relação entre o cálcio solúvel $\left(\mathrm{Ca}^{++}\right)$e os níveis da necessidade de gesso (N N G) das amostras de solos $\mathrm{S}_{1}$ e $\mathrm{S}_{2}$

magnésio os baixos teores encontrados do elemento após a aplicação dos tratamentos podem ser explicados em razão deste elemento não entrar na composição química do gesso em quantidades mínimas, mas só como contaminante $(\mathrm{MgO})$ e também por ter sido removido pela lâmina de lixiviação.

As concentrações observadas para sódio solúvel indicaram que a variável em estudo foi alterada pelas quantidades crescentes do corretivo aplicado (Tabela 3). Os níveis de 50 a $100 \%$ da necessidade de gesso se apresentaram mais eficientes na remoção do sódio solúvel, fato este explicado pela maior solubilização do gesso nos tratamentos enquanto nos demais níveis ocorreu redução em menor escala da concentração de sódio solúvel, independente da quantidade de gesso aplicada. Melo et al. (2008) citam que a solubilidade do gesso depende ainda de outros fatores, tais como concentração de cloreto, granulometria e temperatura.

As amostras de solo originais utilizadas nesta pesquisa apresentavam quantidades elevadas de sódio e cloreto no extrato de saturação antes da aplicação dos tratamentos (Tabela 1), o que contribuiu para maior solubilidade do gesso adicionado especialmente para a amostra de solo $\mathrm{S}_{2}$, o que favoreceu o deslocamento do sódio do complexo sortivo para a solução do solo e em seguida remoção pela água de drenagem.

As relações entre os $\mathrm{NNG} \mathrm{e} \mathrm{Na}^{+}$solúvel foram testadas. Os dados apresentados indicam coeficientes de determinação altamente significativos $\left(\mathrm{R}^{2}=0,98\right.$ e 0,99$)$, que se ajustaram ao modelo quadrático (Figura 2). Nota-se ainda que as reações de substituição entre o sódio da forma trocável para a solúvel dependem da quantidade de gesso aplicada às amostras de solo. Esta tendência foi basicamente a mesma em trabalhos realizados por outros autores em relação à troca iônica do sódio,
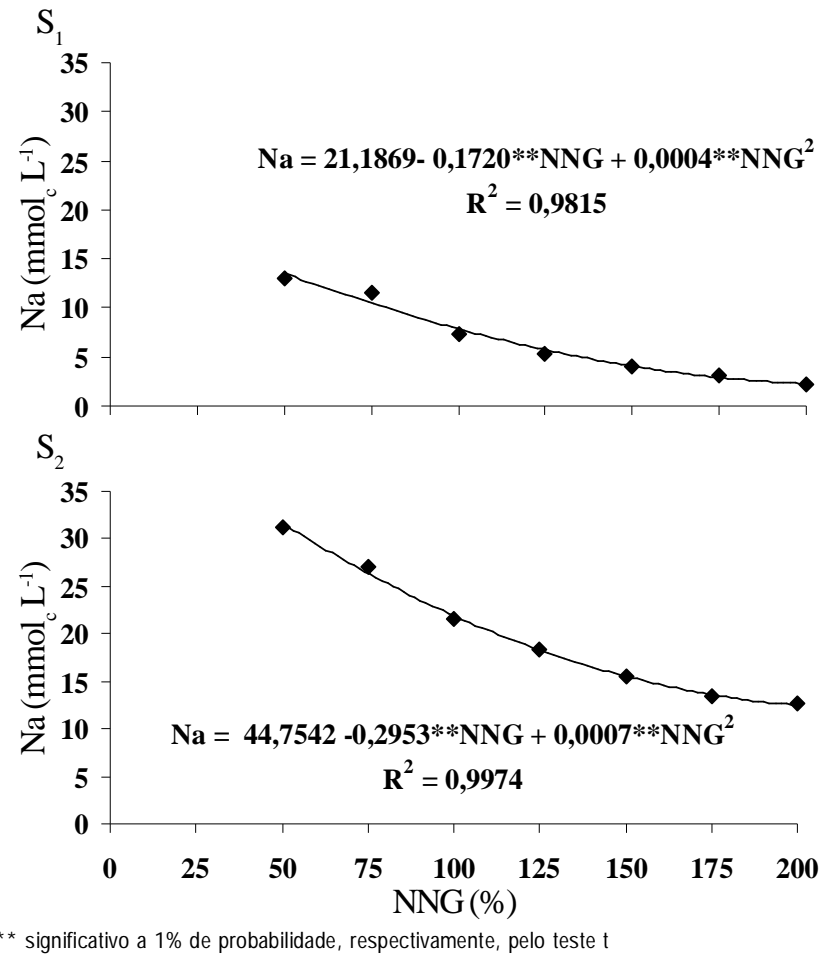

Figura 2. Relação entre o sódio solúvel $\left(\mathrm{Na}^{+}\right)$e os níveis da necessidade de gesso (N N G ) das amostras de solos $\mathrm{S}_{1}$ $\mathrm{eS}_{2}$

da forma trocável para a solúvel (Gobran et al., 1982; Silveira et al., 2008).

Os resultados máximos obtidos para CE no extrato de saturação dos solos foram de 2,10 e 3,93 dS m ${ }^{-1}$, mesmo após a aplicação de quantidades crescentes do corretivo e da lâmina de lixiviação de $3 \mathrm{VP}$, comprovando a eficiência dos tratamentos na diminuição do caráter salino de ambas as amostras de solo. Este efeito pode ser atribuído ao equilíbrio químico estabelecido entre a fração sólida e a líquida dos solos, após a incorporação do gesso ao longo da camada de $25 \mathrm{~cm}$ de profundidade e posterior aplicação de lâmina de lixiviação, o que contribuiu, sobremaneira, para a substituição do sódio do complexo de troca pelo cálcio oriundo do gesso, reduzindo a dupla camada difusa e aumentando a condutividade hidráulica saturada o que, em consequência, causou remoção de maior quantidade de sais solúveis para a água de drenagem.

Os resultados da pesquisa corroboram aos de Gheyi et al. (1995), que identificaram a eficiência do gesso no aumento da permeabilidade da água e redução da salinidade em um solo salino-sódico do Perímetro Irrigado de Sumé na Paraíba, Brasil.

A análise de regressão para CE e NNG indicou haver alta relação entre essas variáveis (Figura 3). A interferência na quantidade de sais no extrato de saturação após aplicação dos tratamentos pode ser representada por um modelo linear. As aplicações de quantidades crescentes de gesso nas amostras de solo causaram elevação da condutividade elétrica do extrato de saturação, para o solo $S_{1}$ o nível de $200 \%$ da necessidade de gesso aumentou a CE em 1.44 vez em relação a nível de 50\%, enquanto para o solo $\mathrm{S}_{2}$ observou-se incremento da CE em 1.27 vez com o maior nível de gesso aplicado; entretanto, os níveis de corretivo adicionados não elevaram o valor da CE para deixar 
as amostras de solo com caráter salino $\left(\mathrm{CE}>4 \mathrm{dS} \mathrm{m} \mathrm{m}^{-1}\right)$. Este efeito também foi constatado por Melo et al. (2008) em estudos realizados com duas amostras de solo afetadas por sais e sódio no Perímetro Irrigado de Custódia, ao aplicar quantidades crescentes de gesso seguido de uma lâmina de lixiviação de três vezes o volume de poros.

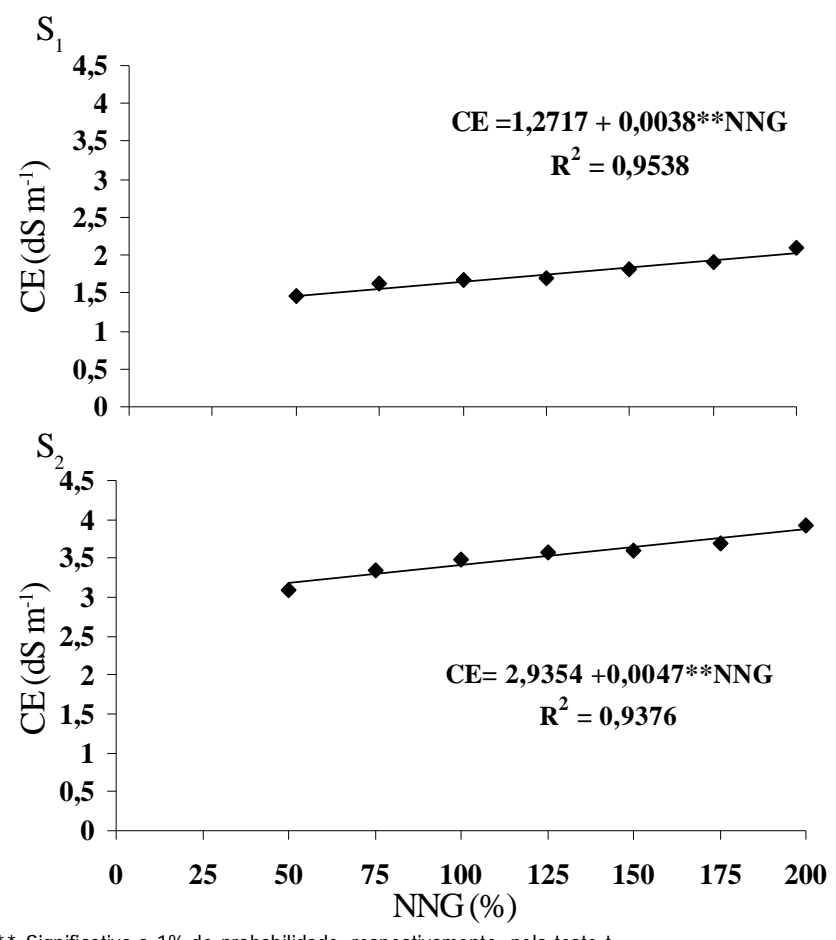

* Significativo a $1 \%$ de probabilidade, respectivamente, pelo teste $t$

Figura 3. Relação entre a condutividade elétrica (CE) e os níveis da necessi dade de gesso (NNG) das amostras de solos $_{1}$ e $\mathrm{S}_{2}$

Os valores apresentados na Tabela 3 para relação de adsorção de sódio (RAS) indicam que houve efeito na variável avaliada após aplicação de gesso. Os níveis de 50, 75 e 100\% provocaram redução mais acentuada da RAS em virtude da maior solubilidade inicial do corretivo já incorporado aos tratamentos de 125 a $200 \%$, que se mostraram menos eficientes, o que gerou redução, embora em menor proporção, da variável em estudo, independente da quantidade de gesso adicionada.

A aplicação de níveis a partir de $100 \%$ da necessidade de gesso causou redução da RAS para valores $<13\left(\mathrm{mmol} \mathrm{L}^{-1}\right)^{1 / 2}$ corrigindo o caráter sódico dos solos em estudo. Constata-se ainda que a substituição do sódio trocável pelo cálcio da solução do solo não depende exclusivamente da quantidade de gesso adicionada haja vista que este processo também é influenciado pela velocidade de infiltração de água no solo e pela quantidade e qualidade da água aplicada na superfície das colunas de solo para lavagem de sais. Tal comportamento também foi observado por Barros et al. (2004), ao constatarem que o gesso mineral aplicado em solos salino-sódicos diminui a sodicidade e aumenta a dinâmica da água no solo, em virtude do deslocamento dos íons, especialmente o sódio, dos sítios de troca e microporos para a lâmina de lixiviação.

As análises de regressão das variáveis NNG e RAS se ajustaram ao modelo quadrático (Figura 4) e apresentaram valores significativos para a variável dependente em estudo, fato este explicado pela eficiência do gesso na correção da sodicidade, pois a aplicação do corretivo causou decréscimo do sódio e aumento do cálcio no extrato de saturação, após a aplicação dos tratamentos e da lâmina de lixiviação de 3VP. Os resultados obtidos nesta pesquisa também foram coerentes com os constatados por Barros et al. (2005) e Melo et al. (2008), que verificaram que a aplicação do nível de $100 \%$ da necessidade de gesso promoveu redução da sodicidade de amostras de solos salino-sódicos coletadas no Perímetro Irrigado de Custódia.

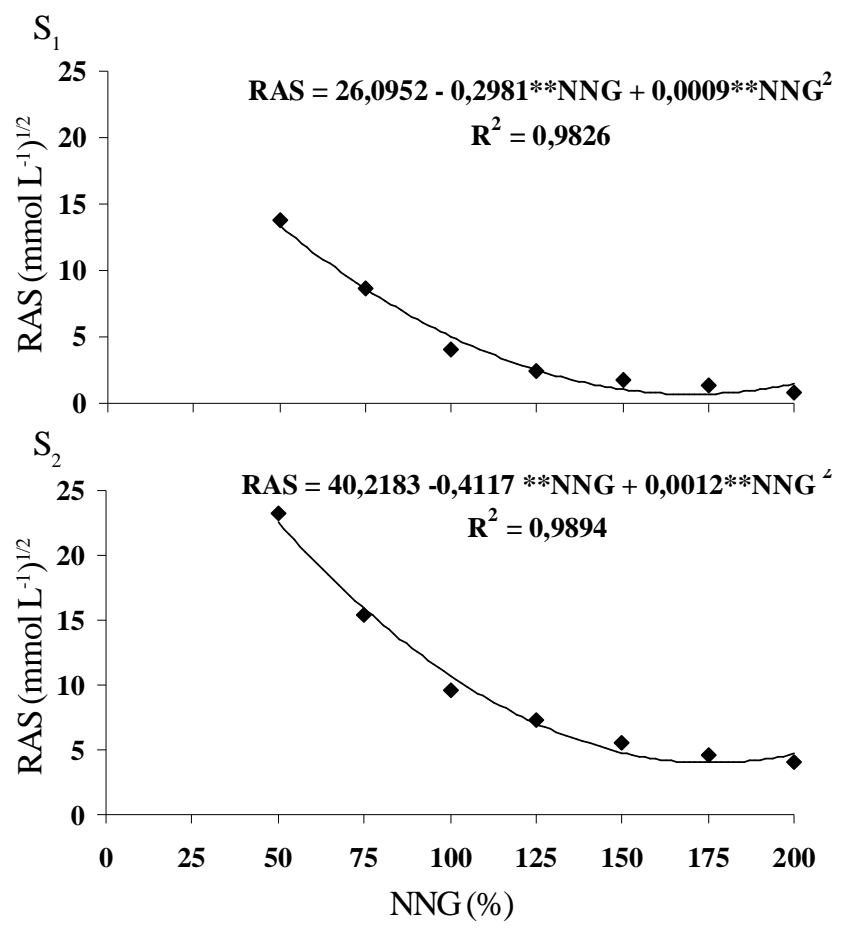

** Significativo a $1 \%$ de probabilidade, respectivamente, pelo teste $t$

Figura 4. Relação entre a relação de adsorção de sódio (RAS) e os níveis da necessidade de gesso (N NG) das amostras de solos $\mathrm{S}_{1}$ e $\mathrm{S}_{2}$

Leite et al. (2007) constataram, em estudos realizados com dois solos coletados nos Perímetros Irrigados dos municípios de Condado e Sousa, PB, que o aumento das doses de gesso exerceu maior redução da sodicidade; no entanto, no solo de Souza houve maior declínio da sodicidade em razãao da sua maior percentagem da fração areia em relação ao solo mais argiloso de Condado, o que contribuiu para maior troca entre o sódio do solo pelo cálcio do corretivo e, em contrapartida, também maior lixiviação de sais.

\section{CONCLUSÕES}

1. O nível de $100 \%$ da necessidade de gesso causou diminuição da sodicidade para valores de RAS $<13\left(\mathrm{mmol} \mathrm{L}^{-1}\right)^{1 / 2}$ apresentando-se como método eficiente na redução dos teores de sódio em áreas afetadas por sais.

2. A lâmina de lixiviação de três vezes o volume de poros reduziu a $\mathrm{CE}$ do extrato de saturação para valores $<4 \mathrm{dS} \mathrm{m}{ }^{-1}$, 
sendo indicada para a correção da salinidade dos solos em estudo.

\section{LITERATURA CITADA}

Barros, M. de F. C.; Bebé, F. V.; Santos, T. O.; Campos, M. C. C. Influência da aplicação de gesso para correção de um solo salino sódico cultivado com feijão caupi. Revista de Biologia e Ciências da Terra, v.9, p.77-82, 2009.

Barros, M. de F. C.; Fontes, M. P. F.; Alvarez V., V. H.; Ruiz, H. A. Recuperação de solos afetados por sais pela aplicação de gesso de jazida e calcário no Nordeste do Brasil. Revista Brasileira deEngenharia Agrícolae Ambiental, v.8, p.59-64, 2004.

Barros, M. de F. C.; Fontes, M. P. F.; Alvarez V., V. H.; Ruiz, H. A. Aplicação de gesso e calcário na recuperação de solos salino-sódicos do Estado de Pernambuco. Revista Brasileira de Engenharia Agrícola e Ambiental, v.9, p.320-326, 2005.

Barros, M. de F. C.; Magalhães, A. F. Avaliações de métodos de determinação da necessidade de gesso em solos salinosódicos. Revista Brasileira de Ciência do Solo, v.13, p.119123, 1989.

Barros, M. de F. C.; Santos, P. M.; Melo, R. M.; Ferraz, F. B.; Avaliação de níveis para correção da sodicidade de solos. Revista Brasileira de Ciências Agrárias, v.1, p.17-21, 2006.

EMBRAPA - Empresa Brasileira de Pesquisa Agropecuária. Manual de métodos de análises de solo. 2.ed. Rio de Janeiro: EMBRAPA, 1997. 212p.

Fageria, N. K.; Gheyi, H. R. Melhoramento genético das culturas e seleção de cultivares. In: Gheyi, H. R.; Queiroz, J. E.; Medeiros, J. F. de. (ed.) Manejo e controle da salinidade na agricultura. Campina Grande: UFPB, 1997. 20p.

Ferreira, D. F. SISVAR: Um programa para análises e ensino de estatística. Revista Symposium, v.6, p.36-41, 2008.

Gheyi, H. R.; Azevedo, N. C.; Batista, M. A. F.; Santos, J. G. R. Comparação de métodos na recuperação de solo salinosódico. Revista Brasileira de Ciência do Solo, v.19, p.173178, 1995.

Gobran, G. R.; Dufey, J. E.; Laudelout, H. The use of gypsum for preventing soilk sodification: Effect of gypsum particle size and location in the profile. Jornal Soil Science, v.33, p.309-316, 1982.
Horney, R. D.; Taylor, B.; Munk, D. S.; Roberts, B. A., Lesch, S. M.; Plant, R. E. Development of practical site-specific management methods for reclaiming salt-affected soil. Computers and Electronics in Agriculture, v.46, p.379-397, 2005.

Keiffer, C. H.; Ungar, I. A. Germination and establishment of halophytes on brine-affected soils. Journal of Applied Ecology, v.39, p.402-415, 2002.

Leal, G. I.; Accioly, A de M. A.; Nascimento do A.W.C.; Freire, S dos G. B. M.; Montenegro, A de A. A.; Ferreira, L. de F. Fitorremediação de solo salino por Atriplex nummularia e gesso de jazida. Revista Brasileira de Ciência do Solo, v.32, p.1065-1072, 2008.

Leite, E. M.; Cavalcante L. F.; Diniz, A. A.; Santos R. V.; Alves G. da S.; Cavalcante I. H. L. Correção da sodicidade de dois solos irrigados em resposta à aplicação de gesso agrícola. Irriga, v.12, p.168-176, 2007.

Magalhães, A. F. Métodos de análise químicas para solos salinos e sódicos. Recife: UFRPE, 1987. 30p.

Melo, R. M.; Barros, M. F. C.; Santos, P. M.; Rolim, M. M. Correção de solos salino-sódicos pela aplicação de gesso mineral. Revista Brasileira de Engenharia Agrícola e Ambiental, v.12, p.376-380, 2008.

Oliveira, L. B. de; Ribeiro, M. R.; Ferreira, M. da G. de V. X.; Lima, J. F. W. F. de,; Marques, F. A. Inferências pedológicas aplicadas ao Perímetro Irrigado de Custódia, PE. Pesquisa Agropecuária Brasileira, v.37, p.1477-1486, 2002.

Richards, L. A. Diagnosis and improvement of saline and alkali soils. Washinton: U. S. Department of Agriculture, 1954. 160p. Agricultural Handbook, 60.

Ruiz, H. A., Sampaio, R. A., Oliveira M. de, Alvarez V., V. H. Características químicas de solos salino-sódicos submetidos a parcelamento da lâmina de lixiviação. Pesquisa Agropecuária Brasileira, v.39, p.1119-1126, 2004.

Schoonover, W. R. Examination of soils for alkali. Berkeley: University of California. Extension Service, 1952. Mimeographed

Silveira, K. R.; Ribeiro, M. R.; Oliveira, L. B.; Heck, R. J.; Silveira, R. R. Gypsum saturated water to reclaim alluvial saline sodic and sodic soils. Scientia Agrícola, v.65, p.69-76, 2008. 